\title{
Scaling Methodology for Buckling of Sandwich Composite Cylindrical Structures
}

\author{
Ines Uriol Balbin ${ }^{1}$ and Chiara Bisagni ${ }^{2}$ \\ Delft University of Technology, Delft, 2629HS, Netherlands \\ Marc R. Schultz ${ }^{3}$ and Mark W. Hilburger ${ }^{4}$ \\ NASA Langley Research Center, Hampton, VA 23681, USA
}

\begin{abstract}
The study of the buckling behavior of large shell structures through full-size tests can be complex and expensive. Therefore, scaled structures are often preferred to investigate the buckling behavior efficiently. However, it can be difficult to design scaled structures that are representative of the full-scale structures. Herein, an analytical scaling methodology for compression-loaded sandwich composite cylinders based on the nondimensionalization of the buckling equations is presented. The methodology is used to develop scaled configurations that show a similar buckling response. Both the baseline and the scaled configurations are verified by finite-element analysis. Limitations of the methodology are discussed and are a result of neglecting the flexural anisotropy and the transverse shear compliance.
\end{abstract}

\section{Nomenclature}

$\mathrm{a}_{\mathrm{ij}} \quad=$ Membrane compliance matrix

$\mathrm{D}_{\mathrm{ij}} \quad=$ Bending stiffness matrix

$\mathrm{F}=$ Nondimensional stress function

$\mathrm{G}_{12} \quad=$ In-plane shear modulus

$\mathrm{G}_{13}, \mathrm{G}_{23}=$ Core transverse shear moduli

$\mathrm{K}=$ Nondimensional load parameter, $\mathrm{N}_{11} \mathrm{R}^{2} / \sqrt{D_{11} D_{22}}$

$\mathrm{L} \quad=$ Cylindrical shell length

$\mathrm{M}_{\mathrm{ij}} \quad=$ Nondimensional moments

$\mathrm{m} \quad=$ Number of axial half waves

$\mathrm{n} \quad=$ Number of circumferential full waves

$\mathrm{N}_{11} \quad=$ Axial force resultant, $\mathrm{P} / 2 \pi \mathrm{R}$

$\mathrm{P} \quad=$ Axial load

$\mathrm{R}=$ Cylindrical midsurface shell radius

$\mathrm{t}_{\text {core }}=$ Sandwich core thickness

$\mathrm{t}_{\text {ply }} \quad=$ Ply thickness

$\mathrm{W} \quad=$ Radial displacement

$\mathrm{W}=$ Nondimensional radial displacement, $\mathrm{w} / \sqrt[4]{\mathrm{a}_{11} \mathrm{a}_{22} \mathrm{D}_{11} \mathrm{D}_{22}}$

$\mathrm{x}=$ Axial coordinate

$\mathrm{z}_{1} \quad=$ Nondimensional axial coordinate, $\mathrm{x} / \mathrm{L}$

$\mathrm{z}_{2}=$ Nondimensional circumferential coordinate, $\Theta$

$\mathrm{Z}_{2} \quad=$ Batdorf-Stein nondimensional parameter, $R /\left(\sqrt{12} \sqrt[4]{a_{11} a_{22} D_{11} D_{22}}\right)$

$\alpha_{\mathrm{b}} \quad=$ Nondimensional parameter, $(\mathrm{R} / \mathrm{L}) \sqrt[4]{\mathrm{D}_{11} / \mathrm{D}_{22}}$

\footnotetext{
${ }^{1} \mathrm{PhD}$ student, Faculty of Aerospace Engineering, Kluyverweg 1.

${ }^{2}$ Full Professor, Faculty of Aerospace Engineering, Kluyverweg 1, AIAA Associate Fellow.

${ }^{3}$ Research Aerospace Engineer, Structural Mechanics and Concepts Branch, 8 West Taylor St, Mail Stop 190, AIAA Senior Member.

${ }^{4}$ Senior Research Engineer, Structural Mechanics and Concepts Branch, 8 West Taylor St, Mail Stop 190, AIAA Senior Member.
}

American Institute of Aeronautics and Astronautics 


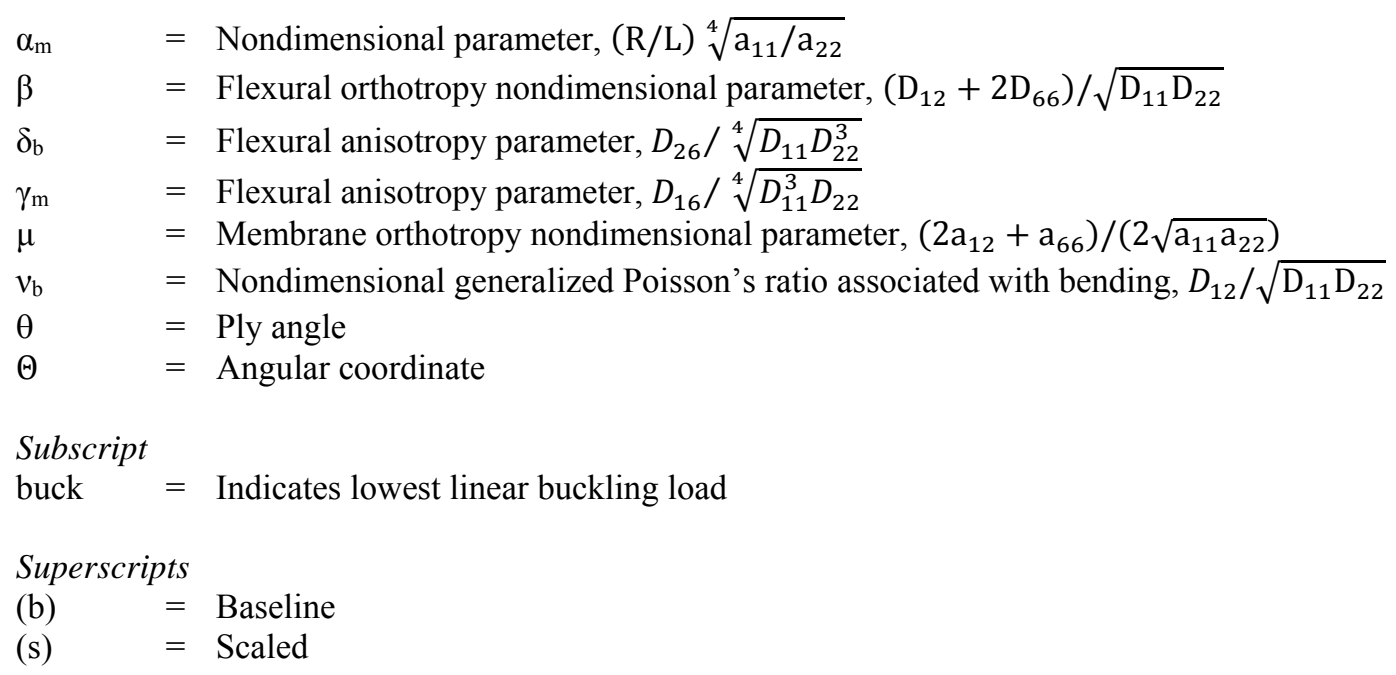

\section{Introduction}

Q uckling is major consideration in the design of lightweight shell structures, so laboratory-scale cylindrical shells Bare commonly used for the experimental study of buckling behavior ${ }^{1}$ to reduce the cost of experimental validation and certification of large structures. It has been shown that such laboratory-scale cylinders can be effective for developing design guidelines for launch-vehicle shell structures. ${ }^{2}$ However, scaling can be difficult in shell structures due to the small thickness, manufacturing considerations, and the fact that the buckling response is closely related to the relative stiffness properties of the structure.

There is an increasing interest in the use of sandwich composite structures for space launch vehicles with laminated facesheets and honeycomb core. ${ }^{3}$ The use of sandwich composites for launch-vehicle structures can provide good stiffness, strength, and structural efficiency. However, a large number of parameters play an important role in both the scaling and the buckling response. The high imperfection sensitivity of thin-shell structures ${ }^{4}$, and the dependence on the boundary conditions add difficulty to predicting the buckling response. Thus, a careful design of the scaled structure and verification by finite-element analysis is required.

Historically, scaled models have been built through the use of dimensional analysis to obtain similarity conditions. ${ }^{5}$ This dimensional analysis is employed to deduce a form of the system of characteristic equations. Complete similarity is obtained when all the independent dimensionless parameters are the same for both the scaled and baseline configurations. The main disadvantage of this methodology is the difficulty in identifying the scaling laws, due to the large number of design parameters.

Similarity theory based on governing equations proved to be effective in the design of scaled structures with complete and partial similarity. This was shown by Rezaeepazhand, et $a .^{6}{ }^{6}$ who studied the case of laminated cylindrical shells under axial compressive load. Later, Hilburger, et al. ${ }^{7}$ used nondimensional parameters, based on Reissner-Mindlin plate theory, to obtain scaling laws for noncircular sandwich composite structures subjected to combined loads. The main advantage is that the scaling laws by Rezaeepazhand and by Hilburger are deduced from properties of the structure and their relationship through the governing equations. The difficulty is to simultaneously fulfill all the scaling laws while remaining within the design and manufacturing constraints. Furthermore, lack of perfect similarity can limit the applicability of the results.

The objective of the current research was to develop a scaling methodology based on the nondimensional buckling governing equations and parameters. The nondimensional parameters were previously defined by Schultz and Nemeth ${ }^{8}$ to characterize the buckling of compression-loaded orthotropic cylinders. This methodology will be used to characterize the behavior of large sandwich composite cylindrical shells subjected to axial compression through analytically scaled cylindrical shells that can be computationally verified, manufactured, and tested in a laboratory.

\section{Scaling Methodology}

In the current study, the cylindrical structure that needs to be scaled, referred to as the baseline cylinder, is a cylindrical sandwich composite shell with carbon fiber facesheets and aluminum honeycomb core. The result of the structural scaling, referred to as the scaled cylinder, is also a sandwich composite cylinder with the same facesheet and core materials. The two cylinders, as well as considered geometric variables and the coordinate system, are presented in Figure 1. The stiffness properties of such composite structures can be varied by changing the facesheet

American Institute of Aeronautics and Astronautics 
stacking sequences. In this study, stacking sequences that depend on only one variable, a ply angle $\theta$ with respect to the axial direction, were considered. Hence, the facesheet stiffness properties were defined by a layup family and a single parameter.

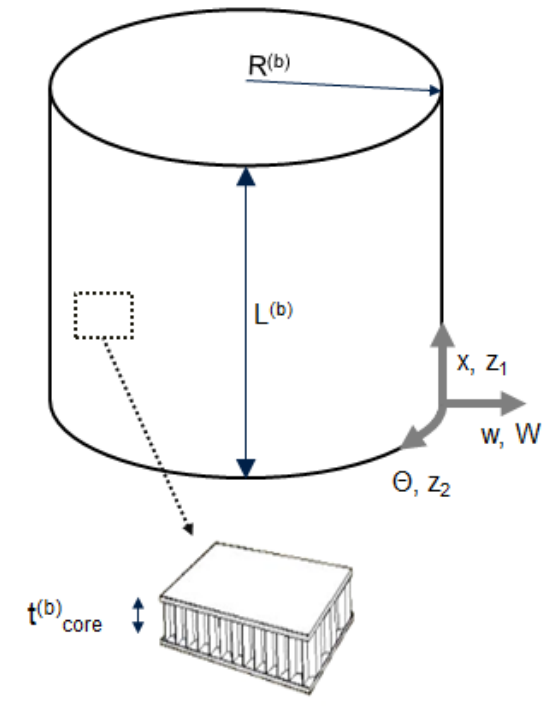

(a) Baseline

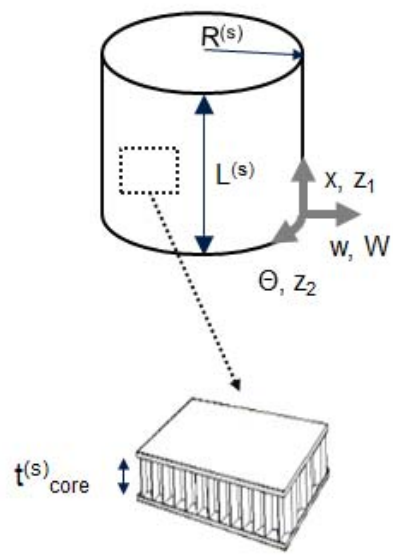

(b) Scaled

Figure 1. Geometric variables and coordinate system of the baseline and the scaled.

The scaling procedure was applied to two baseline, (b), designs, each with radius, $\mathrm{R}^{(\mathrm{b})}$, of $1202 \mathrm{~mm}$ and length, $\mathrm{L}^{(\mathrm{b})}$, of $2305 \mathrm{~mm}$, which results in the ratio $\mathrm{R}^{(\mathrm{b})} / \mathrm{L}^{(\mathrm{b})}=0.52$. The facesheets were made of IM7/8552 carbon fiber whose properties are reported in Table 1. The chosen baseline designs were simplified subscale launch-vehicle structures similar to those used as large-scale test articles in related NASA work. ${ }^{9}$ Specifically, the stacking sequence of the facesheets is $[60 /-60 / 0]_{\mathrm{s}}$ for the first baseline cylinder (Baseline 1), and [30/-30/90/0 $]_{\mathrm{s}}$, for the second cylinder (Baseline 2). The first and second baseline cylinder aluminum honeycomb cores, whose properties are reported in Table 2, have thicknesses, $\mathrm{t}^{(\mathrm{b})}$ core, of $5.08 \mathrm{~mm}$ and $7.62 \mathrm{~mm}$, respectively.

Table 1. Facesheet properties IM7/8552 ${ }^{10}$

\begin{tabular}{ccccc}
\hline $\mathrm{E}_{11}(\mathrm{MPa})$ & $\mathrm{E}_{22}(\mathrm{MPa})$ & $v$ & $\mathrm{G}_{12}(\mathrm{MPa})$ & $\mathrm{t}_{\mathrm{ply}}(\mathrm{mm})$ \\
\hline 140,928 & 9721 & 0.356 & 4688 & 0.18 \\
\hline
\end{tabular}

Table 2. Core properties aluminum honeycomb 3.1 pcf 1/8-5056-.0007

\begin{tabular}{ccccc}
\hline $\mathrm{E}_{11}(\mathrm{MPa})$ & $v$ & $\mathrm{G}_{12}(\mathrm{MPa})$ & $\mathrm{G}_{13}(\mathrm{MPa})$ & $\mathrm{G}_{23}(\mathrm{MPa})$ \\
\hline 6.7 & 0.3 & 1.5 & 310 & 138 \\
\hline
\end{tabular}

The developed methodology was used to obtain scaled, (s), configurations representative of the baseline structures. The geometry defined by $\mathrm{R}^{(\mathrm{s})}$ and $\mathrm{L}^{(\mathrm{s})}$ had to be determined. Additionally, the number of plies, the stacking sequence of the facesheets, and the core thickness, $\mathfrak{t}^{(\mathrm{s})}$ core had to be decided. In the current effort, two families of stacking sequences were considered for the facesheets, and with both families the ply stacking sequence was a function of only one variable, which made the procedure possible. These facesheet stacking sequence families are:

1. A symmetric balanced four-ply laminate: $[\theta /-\theta]$ s

2. A three-ply balanced unsymmetric laminate: $[\theta /-\theta / 0]$ 
The scaling methodology was based on the nondimensional form of the Donnell-Mushtari-Vlasov buckling equations as defined by Nemeth ${ }^{11,12}$, and specialized for use with compression-loaded circular cylinders by Schultz and Nemeth ${ }^{8}$. The buckling equations were formulated under the assumptions of small strains, and neglect transverseshear deformations and initial geometric imperfections. It was understood that these last two assumptions may not be universally valid. The considered equations were formulated by treating the entire sandwich structure as a balanced and symmetric laminate, neglecting bend-twist anisotropy effects. With these considerations, the nondimensional governing equations of compatibility and equilibrium, Eq. (1) and (2), are:

- Compatibility equation

$$
\alpha_{\mathrm{m}}^{2} \mathrm{~F}_{\mathrm{z}_{1} \mathrm{z}_{1} \mathrm{z}_{1} \mathrm{z}_{1}}+\frac{1}{\alpha_{\mathrm{m}}^{2}} \mathrm{~F}_{, \mathrm{z}_{2} \mathrm{z}_{2} \mathrm{z}_{2} \mathrm{z}_{2}}+2 \mu \mathrm{F}_{, \mathrm{z}_{1} \mathrm{z}_{1} \mathrm{z}_{2} \mathrm{z}_{2}}-\sqrt{12} \mathrm{z}_{2} \mathrm{~W}_{, \mathrm{z}_{1} \mathrm{z}_{1}}=0
$$

- Equilibrium equation

$$
\alpha_{\mathrm{b}}^{2} \mathrm{~W}_{, \mathrm{z}_{1} \mathrm{z}_{1} \mathrm{z}_{1} \mathrm{z}_{1}}+\frac{1}{\alpha_{\mathrm{b}}^{2}} \mathrm{~W}_{, \mathrm{z}_{2} \mathrm{z}_{2} \mathrm{z}_{2} \mathrm{z}_{2}}+2 \beta \mathrm{W}_{, \mathrm{z}_{1} \mathrm{z}_{1} \mathrm{z}_{2} \mathrm{z}_{2}}+\sqrt{12} \mathrm{z}_{2} \mathrm{~F}_{, \mathrm{z}_{1} \mathrm{z}_{1}}-\mathrm{KW}_{, \mathrm{z}_{1} \mathrm{z}_{1}}=0
$$

where $\mu, \beta, \alpha_{\mathrm{m}}, \alpha_{\mathrm{b}}, \mathrm{Z}_{2}$, and $\mathrm{K}$ are nondimensional parameters defined below, $\mathrm{F}$ is the nondimensional stress function, and $\mathrm{W}$ is the nondimensional radial displacement given by

$$
\mathrm{W}=\mathrm{w} / \sqrt[4]{\mathrm{a}_{11} \mathrm{a}_{22} \mathrm{D}_{11} \mathrm{D}_{22}}
$$

where $\mathrm{w}$ is the radial displacement, the $\mathrm{a}_{\mathrm{ij}}$ 's are membrane compliances, and the $\mathrm{D}_{\mathrm{ij}}$ 's bending stiffnesses. The subscripts $z_{1}$ and $z_{2}$ represent the derivatives in the axial and circumferential direction in the nondimensional coordinates. The similarity conditions are the nondimensional parameters in these equations.

Using the nondimensional parameters in Eq. (1) and (2), the buckling response was formulated independent of the geometrical parameters. The response was formulated by the six nondimensional parameters presented in Eqs. (4)-(9) as reported in the literature. ${ }^{8}$

The first two parameters $\mu$ and $\beta$ depend only on the components of the in-plane compliance matrix and the bending stiffness matrix:

$$
\begin{gathered}
\mu=\frac{2 a_{12}+a_{66}}{2 \sqrt{a_{11} a_{22}}} \\
\beta=\frac{D_{12}+2 D_{66}}{\sqrt{D_{11} D_{22}}}
\end{gathered}
$$

The parameter $\alpha_{\mathrm{m}}$ establishes a relation between the cylinder radius to length ratio, $\mathrm{R} / \mathrm{L}$, and the membrane compliances, while $\alpha_{b}$ establishes a relation between $\mathrm{R} / \mathrm{L}$ and the bending stiffnesses:

$$
\begin{aligned}
& \alpha_{\mathrm{m}}=\frac{R}{L} \sqrt[4]{\frac{a_{22}}{a_{11}}} \\
& \alpha_{\mathrm{b}}=\frac{R}{L} \sqrt[4]{\frac{\mathrm{D}_{11}}{\mathrm{D}_{22}}}
\end{aligned}
$$

The Batdorf-Stein parameter $Z_{2}$, formally introduced by Nemeth, ${ }^{11}$ relates the radius with the membrane compliances and bending stiffnesses (similar in character to a cylinder radius to thickness ratio, $\mathrm{R} / \mathrm{t}$ ):

$$
Z_{2}=\frac{\mathrm{R}}{\sqrt{12} \sqrt[4]{\mathrm{a}_{11} \mathrm{a}_{22} \mathrm{D}_{11} \mathrm{D}_{22}}}
$$

Finally, the nondimensional load parameter $\mathrm{K}$, relates the axial force resultant $\mathrm{N}_{11}$ with the bending stiffnesses and the midsurface shell radius:

American Institute of Aeronautics and Astronautics 


$$
K=\frac{N_{11} R^{2}}{\sqrt{D_{11} D_{22}}}=\frac{P}{2 \pi R} \frac{R^{2}}{\sqrt{D_{11} D_{22}}}
$$

where $\mathrm{P}$ is the total axial load.

The goal of this study was to develop a methodology to design scaled configurations with nondimensional parameters that match baseline configurations with the nondimensional parameters reported in Table 3 . The innovative aspect of present methodology was that the parameters were decoupled, which allowed each parameter to be calculated in a specific order. The parameter $\mathrm{K}$ was not part of the scaling methodology because it was solved to determine the lowest buckling load.

Table 3. Baseline nondimensional parameters.

\begin{tabular}{cccccc}
\hline & $\mu$ & $\beta$ & $\alpha_{\mathrm{m}}$ & $\alpha_{\mathrm{b}}$ & $\mathrm{Z}_{2}$ \\
\hline Baseline 1 & 1.00 & 1.00 & 0.52 & 0.52 & 107.3 \\
Baseline 2 & 1.51 & 0.79 & 0.60 & 0.60 & 73.9 \\
\hline
\end{tabular}

The first pair of parameters considered in the scaling methodology are the membrane orthotropy parameter, $\mu$, from Eq. (4), and the flexural orthotropy parameter, $\beta$, from Eq. (5). The two parameters relate the in-plane compliance matrix and the bending stiffness matrix parameters, and are function of the material properties; the ply stacking sequence, and the core thickness. In this study, there were two families of stacking sequences, $[\theta /-\theta]_{\mathrm{s}}$ and $[\theta /-\theta / 0]$, with a single variable ply angle $\theta$. With these families of stacking sequences, it was demonstrated that the $\mu$ and $\beta$ parameters strongly depend only on the ply angle $\theta$. This was attributed to the high stiffness of the facesheet, when compared to the core, makes the influence of the core negligible. Therefore, the values of the parameters $\mu$ and $\beta$ were obtained as function of the angle $\theta$ for the two stacking sequence families shown in Figure 2 .

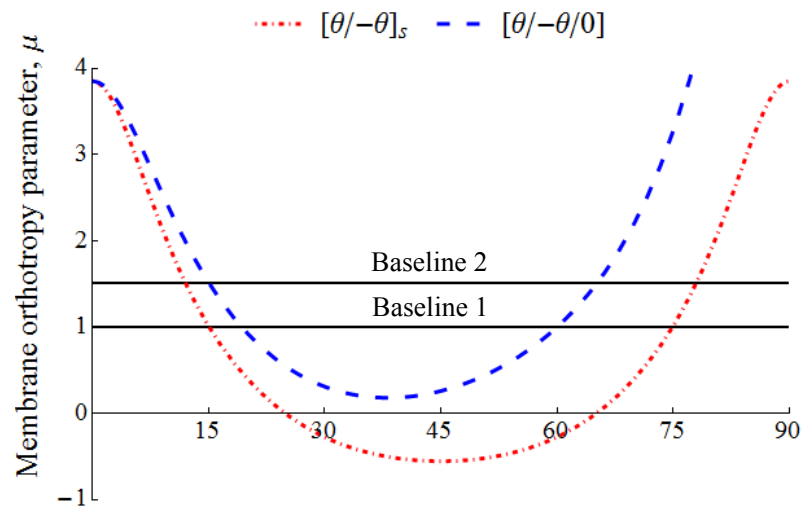

Ply angle, $\theta[\mathrm{deg}]$

(a) Membrane orthotropy parameter, $\mu$

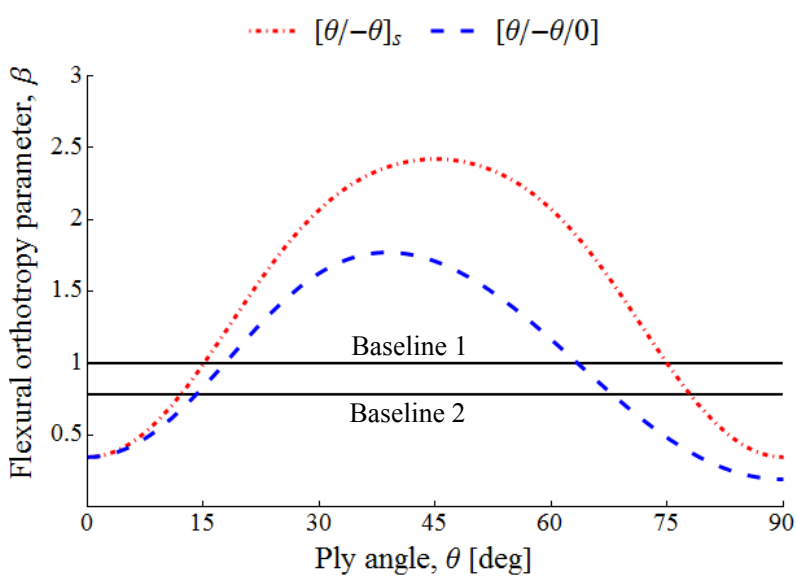

(b) Flexural orthotropy parameter, $\beta$

Figure 2. Membrane, $\mu$, and flexural, $\beta$, orthotropy parameters versus ply angle $\theta$ for scaled facesheet stacking sequences $[\theta /-\theta]_{\mathrm{s}}$ and $[\theta /-\theta / 0]$.

From the curves, the angles required for each stacking sequence in order to maintain the baseline values of $\mu^{(b)}$ and $\beta^{(b)}$ were obtained. For each stacking sequence, the values of angle necessary to match $\mu^{(b)}$ were essentially the same as those necessary to match $\beta^{(b)}$. It is important to note that for the considered laminate families, there were two possible angles that yield equivalent membrane and flexural orthotropy parameters and therefore two possible configurations for the scaled cylinders. Herein, the two configurations obtained from Baseline 1 will be referred to as Scaled 1.1 and Scaled 1.2 for the first family $[\theta /-\theta]_{\mathrm{s}}$ and Scaled 1.3 and Scaled 1.4 for the second family [ $\left.\theta /-\theta / 0\right]$. Similarly, the two configurations obtained from Baseline 2 will be referred to as Scaled 2.1 and Scaled 2.2 for the first family $[\theta /-\theta]_{\mathrm{s}}$ and Scaled 2.3 and Scaled 2.4 for the second family $[\theta /-\theta / 0]$.

The next parameters to evaluate were $\alpha_{\mathrm{m}}$ (Eq. (6)) and $\alpha_{\mathrm{b}}$ (Eq. (7)). Each of these parameters is a function of the ratio $\mathrm{R} / \mathrm{L}$. Both $\alpha_{\mathrm{m}}$ and $\alpha_{\mathrm{b}}$ are also influenced by the ply angle $\theta$ and the core thickness $t_{\text {core. However, the ply angles }}$ were determined in the previous step, and the core-thickness influence is negligible. Therefore, the parameters $\alpha_{\mathrm{m}}$ and 
$\alpha_{b}$ were determined solely by R/L as shown in Figure 3 and Figure 4 for Baseline 1 and Baseline 2, respectively, where the relationships for the scaled layups are presented.

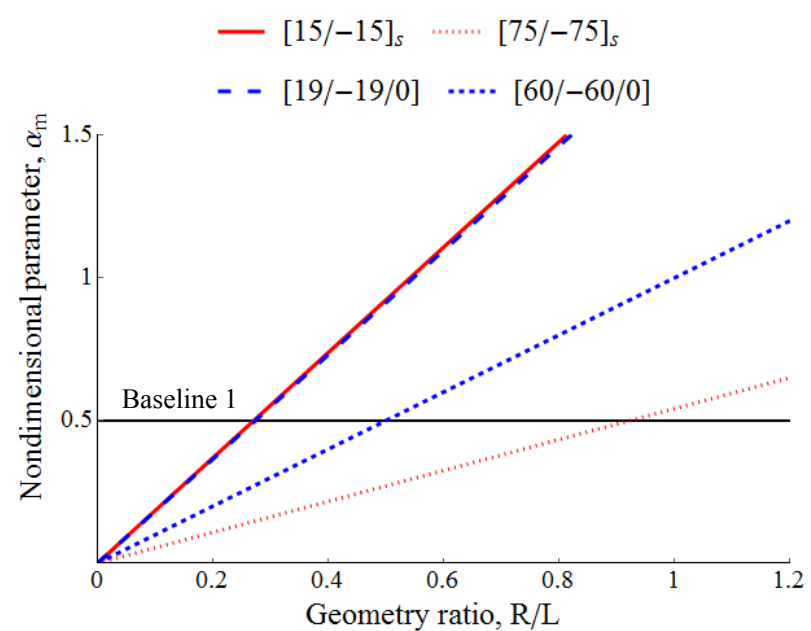

(a) Nondimensional parameter, $\alpha_{\mathrm{m}}$

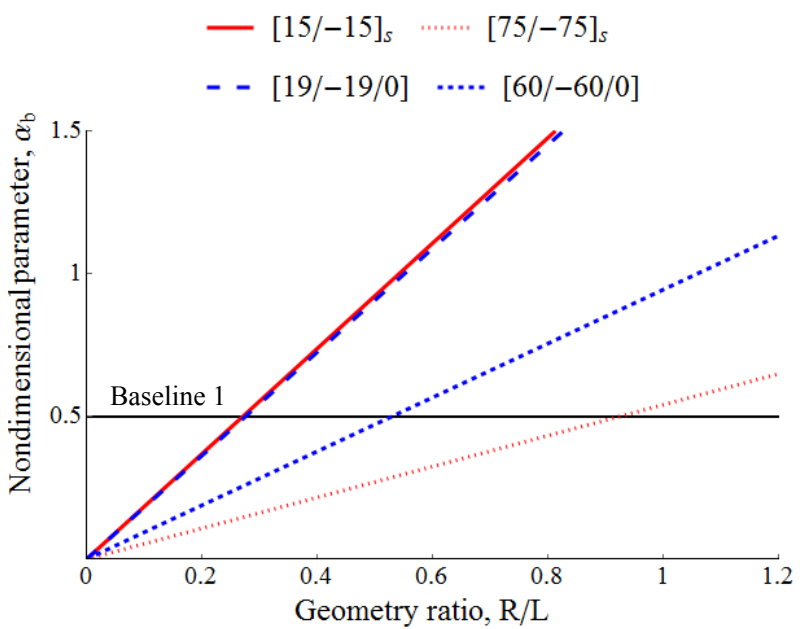

(b) Nondimensional parameter, $\alpha_{\mathrm{b}}$

Figure 3. Parameters $\alpha_{m}$ and $\alpha_{b}$ versus $R / L$ for scaled facesheet stacking sequences for Baseline 1 [60/-60/0]s.

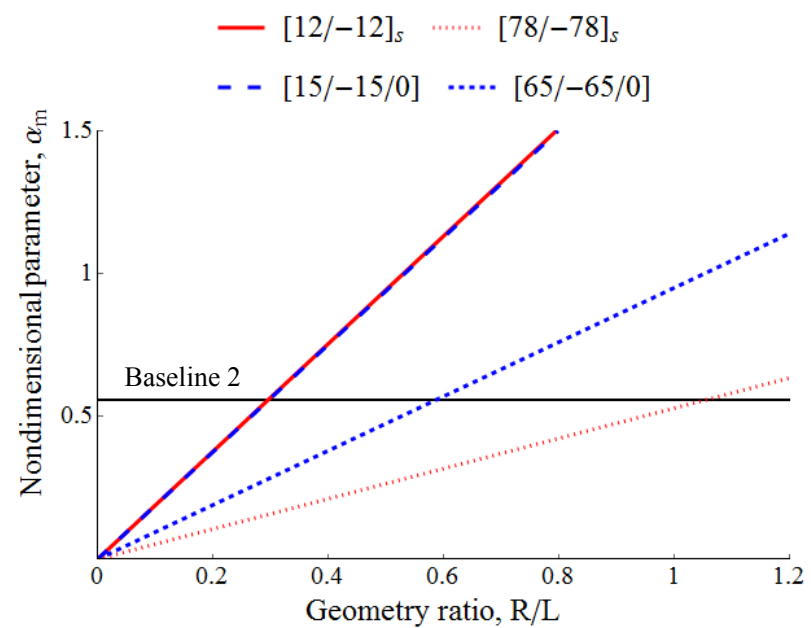

(a) Nondimensional parameter, $\alpha_{\mathrm{m}}$

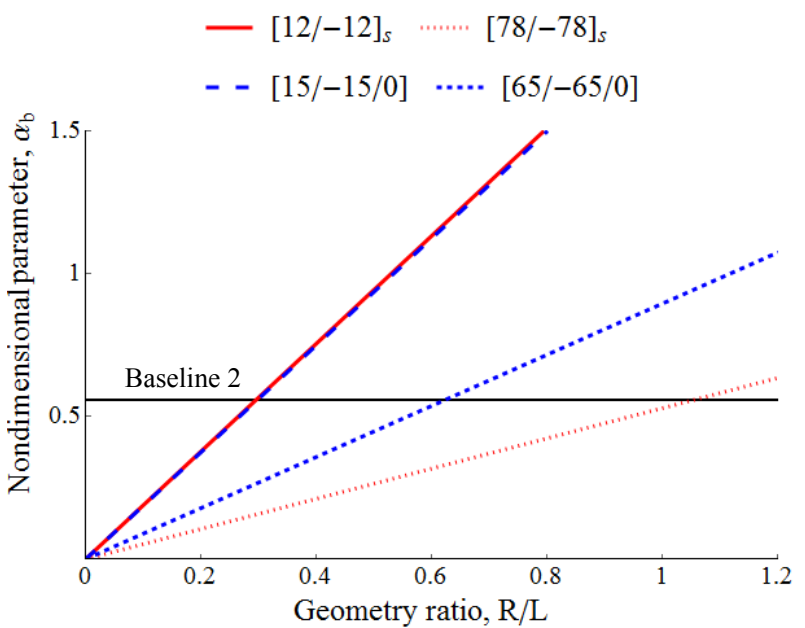

(b) Nondimensional parameter, $\alpha_{\mathrm{b}}$

Figure 4. Parameters $\alpha_{m}$ and $\alpha_{b}$ versus $R / L$ for scaled facesheet stacking sequences for Baseline 2 [30/-30/90/0]s.

It is seen for a given facesheet stacking sequence and for a given ratio R/L, $\alpha_{\mathrm{m}}$ and $\alpha_{\mathrm{b}}$ are essentially equal, and that the relationships between the $\alpha_{\mathrm{m}}$ and $\alpha_{\mathrm{b}}$ parameters and $\mathrm{R} / \mathrm{L}$ are linear. This means that for each value of the $\alpha_{\mathrm{m}}$ and $\alpha_{b}$ parameters, a single solution for the $\mathrm{R} / \mathrm{L}$ was found. The ratio $\mathrm{R} / \mathrm{L}$, reported in Table 4 was important and the value raises concerns of possible global bending if the cylinder is relatively long, while the influence of the boundary conditions can change the buckling response and the imperfection sensitivity when it is relatively short. An important consideration was that the $\mathrm{R} / \mathrm{L}$ for Scaled 1.1, 1.2, and 1.3 was quite different from $\mathrm{R} / \mathrm{L}$ of Baseline 1 . The same occured for Scaled 2.1, 2.2, and 2.3, which were also quite different from Baseline 2. For Scaled 1.1, 1.3, 2.1, and 2.3, the radius was approximately one third of the length and for Scaled 1.2 and 2.2, the radius and length were similar. However, for Scaled 1.4 and 2.4, the $\mathrm{R} / \mathrm{L}$ is similar to their respective baseline.

The final parameter to evaluate is $Z_{2}$ (Eq. (8)), which is function of the radius, the axial and circumferential membrane compliances, and the bending stiffnesses. Given that the facesheet stacking sequence and R/L for the scaled configurations were already selected, the baseline value of $Z_{2}$ can be maintained in the scaled configurations with the right combination of radius, $\mathrm{R}$, and core thickness, $\mathrm{t}_{\text {core. }}$. However, available laboratory testing equipment constrains 
the upper bound for $\mathrm{R}$, and the minimum manufacturable core thickness constrains the lower bound for $\mathrm{t}_{\text {core. In this }}$ study, the radius for all the scaled configurations was fixed and equal to $400 \mathrm{~mm}$ (33.3\% of baseline). The variation of $Z_{2}$ as a function of core thickness was depicted in Figure 5, and the baseline value of $Z_{2}$ was obtained by selecting the core thickness. As observed in Figure 5 and reported in Table 4, the selected values of $t_{\text {core, }}$ within the facesheet stacking sequence family $[\theta /-\theta]_{\mathrm{s}}$, are exactly the same. The core thickness difference within facesheet stacking sequence family $[\theta /-\theta / 0]$ was less than $5 \%$ as reported in Table 4 . It was also noted that the importance of the facesheet stacking sequence family decreases with the desired value of $Z_{2}$ and the increase in the core thickness. The scaled configurations with all the necessary variables, facesheet layup, length, and core thickness, are reported in Table 4.

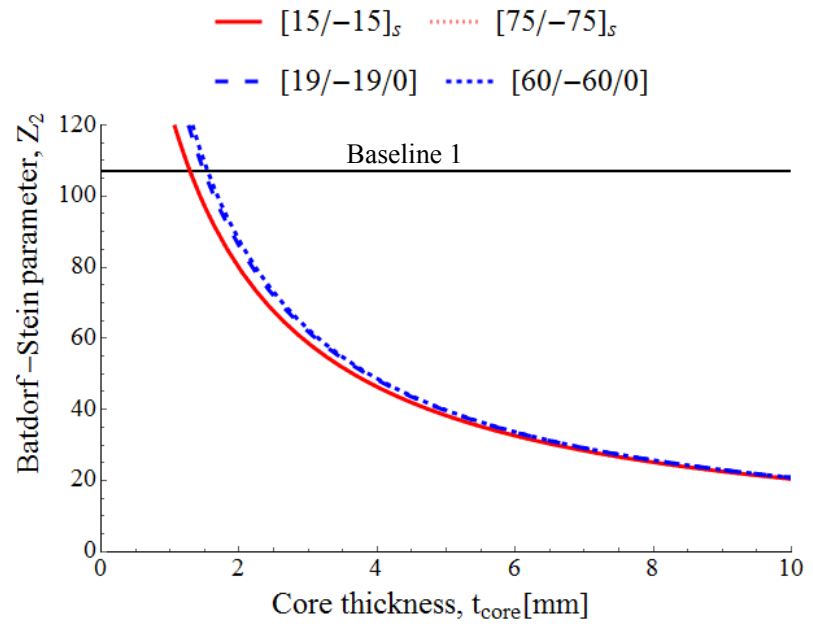

(a) Batdorf-Stein parameter, $\mathrm{Z}_{2}$ for Baseline 1 scaled configurations

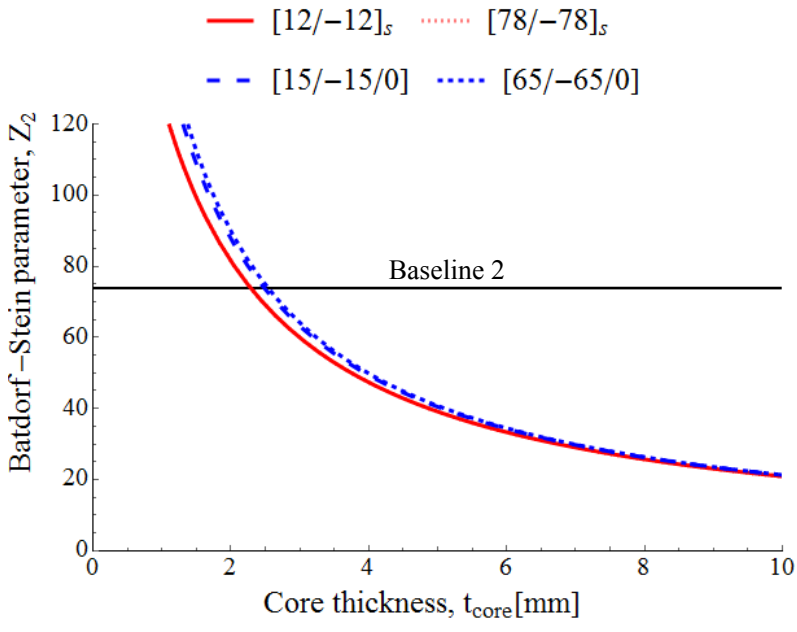

(b) Batdorf-Stein parameter, $Z_{2}$ for Baseline 2 scaled configurations

Figure 5. Batdorf-Stein parameter $Z_{2}$ as function of core thickness $t_{c o r e}$.

Table 4. Geometry of baseline and scaled configurations.

\begin{tabular}{ccccc}
\hline Designation & Layup & $\mathbf{R} / \mathbf{L}$ & Length $(\mathbf{m m})$ & tcore $\left._{\mathbf{m m}}\right)$ \\
\hline Baseline 1 & {$[\mathbf{6 0 / - 6 0 / 0}]_{s}$} & $\mathbf{0 . 5 2}$ & $\mathbf{2 3 0 5}$ & $\mathbf{5 . 0 8}$ \\
\hline Scaled 1.1 & {$[15 /-15]_{\mathrm{s}}$} & 0.29 & 1340 & 1.28 \\
Scaled 1.2 & {$[75 /-75]_{\mathrm{s}}$} & 0.95 & 421 & 1.28 \\
Scaled 1.3 & {$[19 /-19 / 0]$} & 0.29 & 1340 & 1.49 \\
Scaled 1.4 & {$[60 /-60 / 0]$} & 0.52 & 770 & 1.54 \\
\hline Baseline 2 & {$\left[\mathbf{3 0 / - 3 0 / 9 0 / 0 ] _ { s }}\right.$} & $\mathbf{0 . 5 2}$ & $\mathbf{2 3 0 5}$ & $\mathbf{7 . 6 2}$ \\
\hline Scaled 2.1 & {$[12 /-12]_{\mathrm{s}}$} & 0.32 & 1250 & 2.29 \\
Scaled 2.2 & {$[78 /-78]_{\mathrm{s}}$} & 1.12 & 357 & 2.29 \\
Scaled 2.3 & {$[15 /-15 / 0]$} & 0.32 & 1250 & 2.48 \\
Scaled 2.4 & {$[65 /-65 / 0]$} & 0.62 & 645 & 2.54 \\
\hline
\end{tabular}

For the scaled configurations to be tested in a laboratory, certain manufacturing and laboratory equipment constraints apply. For instance, the configurations found may not be manufacturable with the considered materials because the core thickness is very small. However, other core materials are available that can be used instead. The obtained scaled configurations should also have dimensions that fit in standard laboratory test equipment. Thus, restrictions in length, radius, and strength can prevent the testing of some of these configurations. 
The nondimensional parameters for all scaled configurations of both baselines are reported in Table 5. It is seen that most of the scaled parameters matched the associated baseline parameters. However, it was observed that $\beta$ deviated by the highest percentages, up to $20 \%$ for Scaled 1.4, and that the Scaled 1.3, 1.4, 2.3, and 2.4 parameters deviated more than the Scaled 1.1, 1.2, 2.1, and 2.2 parameters, which indicated that the $[\theta /-\theta]_{s}$ layup family was more amenable to precise scaling than the $[\theta /-\theta / 0]$ family.

Table 5. Nondimensional parameters of baseline and scaled configurations.

\begin{tabular}{cccccc}
\hline Designation & $\boldsymbol{\mu}$ & $\boldsymbol{\beta}$ & $\boldsymbol{\alpha}_{\mathbf{m}}$ & $\boldsymbol{\alpha}_{\mathbf{b}}$ & $\mathbf{Z}_{\mathbf{2}}$ \\
\hline Baseline 1 & $\mathbf{1 . 0 0}$ & $\mathbf{1 . 0 0}$ & $\mathbf{0 . 5 2}$ & $\mathbf{0 . 5 2}$ & $\mathbf{1 0 7 . 3}$ \\
\hline Scaled 1.1 & 1.01 & 0.99 & 0.52 & 0.52 & 107.3 \\
Scaled 1.2 & 1.01 & 0.99 & 0.52 & 0.52 & 107.3 \\
Scaled 1.3 & 1.03 & 1.09 & 0.53 & 0.52 & 107.3 \\
Scaled 1.4 & 1.00 & 1.20 & 0.57 & 0.53 & 107.3 \\
\hline Baseline 2 & $\mathbf{1 . 5 1}$ & $\mathbf{0 . 7 9}$ & $\mathbf{0 . 6 0}$ & $\mathbf{0 . 6 0}$ & $\mathbf{7 3 . 9}$ \\
\hline Scaled 2.1 & 1.52 & 0.78 & 0.60 & 0.60 & 73.9 \\
Scaled 2.2 & 1.52 & 0.78 & 0.60 & 0.60 & 73.9 \\
Scaled 2.3 & 1.52 & 0.82 & 0.60 & 0.60 & 73.9 \\
Scaled 2.4 & 1.49 & 0.89 & 0.60 & 0.60 & 73.9 \\
\hline
\end{tabular}

\section{Flexural Anisotropy Effects}

As described thus far, the scaled configurations found were considered similar to the baseline if they have equal nondimensional parameters. However, the considered nondimensional equations were formulated neglecting bendtwist anisotropy and flexural anisotropy. These effects are represented in the constitutive relations (Eq. (10)) by matrix elements that relate the nondimensional bending moments $\left(\mathrm{M}_{11}\right.$ and $\left.\mathrm{M}_{22}\right)$ with the twisting curvature $\left(\partial^{2} W / \partial z_{1} \partial z_{2}\right)$, and by matrix elements that relate the nondimensional twisting moment $\left(\mathrm{M}_{12}\right)$ with the bending curvature in the axial $\partial^{2} W / \partial z_{1}^{2}$ and radial direction $\partial^{2} W / \partial z_{2}^{2}$.

Where

$$
\left[\begin{array}{l}
M_{11} \\
M_{22} \\
M_{12}
\end{array}\right]=\left[\begin{array}{ccc}
\alpha_{b}^{2} & v_{b} & -\gamma_{b} \alpha_{\mathrm{b}} \\
-v_{b} & \frac{1}{\alpha_{b}^{2}} & -\delta_{\mathrm{b}} / \alpha_{\mathrm{b}} \\
-\gamma_{b} \alpha_{\mathrm{b}} & -\delta_{\mathrm{b}} / \alpha_{\mathrm{b}} & \frac{\beta+v_{b}}{2}
\end{array}\right]\left[\begin{array}{c}
\frac{\partial^{2} W}{\partial z_{1}^{2}} \\
\frac{\partial^{2} W}{\partial z_{2}^{2}} \\
2 \frac{\partial^{2} W}{\partial z_{1} \partial z_{2}}
\end{array}\right]
$$

$$
\begin{aligned}
& v_{b}=\frac{D_{12}}{\sqrt{D_{11} D_{22}}} \\
& \gamma_{b}=\frac{D_{16}}{\sqrt[4]{D_{11}^{3} D_{22}}} \\
& \delta_{b}=\frac{D_{26}}{\sqrt[4]{D_{11} D_{22}^{3}}}
\end{aligned}
$$

are additional nondimensional parameters derived by Nemeth ${ }^{12}$ for more general laminated shells.

In order to verify the assumption that flexural anisotropy had a negligible effect on the response, the elements $\delta_{b} / \alpha_{b}$ and $\gamma_{b} \alpha_{b}$ were evaluated and should be significantly lower than the other elements of the matrix. Therefore, they have been compared to the lowest-value element of the matrix, which is $\alpha_{b}^{2}$. This condition is expressed mathematically in Eqs. (14) and (15).

American Institute of Aeronautics and Astronautics 


$$
\begin{aligned}
& O\left(\delta_{b} / \alpha_{b}\right) \ll O\left(\alpha_{b}^{2}\right) \\
& O\left(\gamma_{b} \alpha_{b}\right) \ll O\left(\alpha_{b}^{2}\right)
\end{aligned}
$$

Taking into account these two conditions, a difference of two orders of magnitude was arbitrarily considered sufficient. Hence the ratios of $\delta_{b} / \alpha_{b}$ and $\alpha_{b} \gamma_{b}$ with $\alpha_{b}^{2}$ should be less than $1 \%$. This was fulfilled for the baseline designs. However, these ratios were higher for certain scaled designs, as reported in Table 6 . It is seen that the flexural anisotropy influence was stronger with the facesheet stacking sequences of the $[\theta /-\theta / 0]$ family. In order to abide by the condition of neglecting anisotropy effects, scaled configurations 1.3, 1.4, 2.3, and 2.4 were removed from further consideration as scaled configurations.

Table 6. Flexural anisotropy terms of baseline and scaled configurations.

\begin{tabular}{cccccc}
\hline \hline Designation & Layup & Length $(\mathbf{m m})$ & $\mathbf{t c o r e}_{\mathbf{m}}(\mathbf{m m})$ & $\frac{\boldsymbol{\delta}_{\mathbf{b}} / \boldsymbol{\alpha}_{\mathbf{b}}}{\boldsymbol{\alpha}_{\mathbf{b}}^{2}}(\mathbf{\%})$ & $\frac{\boldsymbol{\alpha}_{\boldsymbol{b}} \boldsymbol{\gamma}_{\mathbf{b}}}{\boldsymbol{\alpha}_{\mathbf{b}}^{2}}(\mathbf{\%})$ \\
\hline Baseline 1 & {$[\mathbf{6 0 / - 6 0 / 0}]_{s}$} & $\mathbf{2 3 0 5}$ & $\mathbf{5 . 0 8}$ & $\mathbf{0 . 7 3}$ & $\mathbf{0 . 5 5}$ \\
\hline Scaled 1.1 & {$[15 /-15]_{\mathrm{s}}$} & 1340 & 1.28 & 9.74 & 0.86 \\
Scaled 1.2 & {$[75 /-75]_{\mathrm{s}}$} & 421 & 1.28 & 3.18 & 2.65 \\
Scaled 1.3 & {$[19 /-19 / 0]$} & 1340 & 1.49 & 46.95 & 5.91 \\
Scaled 1.4 & {$[60 /-60 / 0]$} & 770 & 1.54 & 33.66 & 17.61 \\
\hline Baseline 2 & {$\left[\mathbf{3 0 / - 3 0 / 9 0 / 0 ] _ { s }}\right.$} & $\mathbf{2 3 0 5}$ & $\mathbf{7 . 6 2}$ & $\mathbf{0 . 6 7}$ & $\mathbf{0 . 1 1}$ \\
\hline Scaled 2.1 & {$[12 /-12]_{\mathrm{s}}$} & 1250 & 2.29 & 2.43 & 0.21 \\
Scaled 2.2 & {$[78 /-78]_{\mathrm{s}}$} & 357 & 2.29 & 0.60 & 0.86 \\
Scaled 2.3 & {$[15 /-15 / 0]$} & 1250 & 2.48 & 6.18 & 9.81 \\
Scaled 2.4 & {$[65 /-65 / 0]$} & 645 & 2.54 & 2.90 & 8.83 \\
\hline \hline
\end{tabular}

\section{Methodology Verification}

The scaled configurations obtained with the described methodology had nondimensional parameters similar to the baselines, but they should also have similar buckling responses if they are to be said to represent the behavior of the baselines. Buckling load and buckling mode shape were two such characteristics of buckling behavior compared herein. First, the buckling loads and modes were calculated analytically with the procedure described by Schultz and Nemeth, ${ }^{8}$ from the governing equations (Eqs. (1) and (2)), assuming solutions for $\mathrm{W}$ and $\mathrm{F}$ in the form of double sine series. Next, applying eigenvalue analysis to solve for the lowest buckling value of $\mathrm{K}, \mathrm{K}_{\text {buck }}$, and the buckling mode as described by the number of axial half waves, $\mathrm{m}$, and the number of circumferential full waves, $\mathrm{n}$. Lastly, the boundary conditions used in the present study were simply supported with no radial or circumferential displacements, and have zero bending moment at $z_{1}=0$ and $z_{1}=L$. The obtained buckling loads and modes were reported in Table 7 . It is seen that the buckling mode for all scaled configurations matched the respective baseline buckling mode. It is also seen that the values of $\mathrm{K}_{\text {buck }}$ for all four scaled versions matched the respective baseline values within $0.5 \%$. For reference, the buckling loads, $\mathrm{P}_{\text {buck }}$, calculated according to Eq. (9) are also shown. The scaled buckling loads were within the load range a standard laboratory testing machine can apply $(1500 \mathrm{kN}-2500 \mathrm{kN})$. This was relevant because the ultimate desire for these structures was the ability to test them in the laboratory.

American Institute of Aeronautics and Astronautics 
Table 7. Buckling load and buckling mode.

\begin{tabular}{|c|c|c|c|c|}
\hline Designation & $\begin{array}{c}\text { Axial } \\
\text { half waves, } \\
\text { m }\end{array}$ & $\begin{array}{l}\text { Circumferential } \\
\text { full waves, } n\end{array}$ & $\begin{array}{c}\text { Nondimensional } \\
\text { load parameter, } \\
\text { K }_{\text {buck }} \\
\end{array}$ & $\begin{array}{c}\text { Buckling load, } \\
\mathbf{P}_{\text {buck }}\end{array}$ \\
\hline Baseline 1 & 8 & 9 & 743 & $4485 k N$ \\
\hline Scaled 1.1 & 8 & 9 & 740 & $646 \mathrm{kN}$ \\
\hline Scaled 1.2 & 8 & 9 & 740 & $646 \mathrm{kN}$ \\
\hline Baseline 2 & 4 & 8 & 433 & $8368 \mathrm{kN}$ \\
\hline Scaled 2.1 & 4 & 8 & 431 & $829 \mathrm{kN}$ \\
\hline Scaled 2.2 & 4 & 8 & 431 & $829 \mathrm{kN}$ \\
\hline
\end{tabular}

The analytical procedure described herein leads to the same results as the procedure reported by Vinson and Swieratowki. ${ }^{13}$ Both neglect the transverse shear compliance effects in the core. This was considered a reasonable hypothesis due to the relatively small thickness of the core. However, in order to evaluate transverse-shear-compliance effects, the results were compared to the formulation of Reese and Bert ${ }^{14}$ that considers the transverse shear stiffnesses in the core, $\mathrm{G}_{13}$ and $\mathrm{G}_{23}$, significantly higher than the core in-plane shear stiffness, $\mathrm{G}_{12}$, as shown in Table 2 . The Reese and Bert formulation includes other assumptions and simplifications such as neglecting the in-plane core stiffness. Nevertheless, the comparison was an indication of the influence of the transverse-shear effects that were ignored in the present work. In Table 8, it is seen that the buckling loads calculated from the two formulations differ significantly at both scales; specifically, the Scaled 1.2 and 2.2 configurations show the highest differences of $16.10 \%$ and $14.45 \%$, respectively. This lead to consider that the transverse-shear compliance should be included in the methodology. For the purposes of the current study, the Scaled 1.1 and 2.1 configurations will be further examined herein, since the buckling loads calculated from the two formulations showed a smaller difference, see Table 8.

Table 8. Buckling load for different analytical formulations.

\begin{tabular}{cccc}
\hline Designation & $\begin{array}{c}\text { Analytical Schultz } \\
\text { and Nemeth }\end{array}$ & $\begin{array}{c}\text { Analytical Reese } \\
\text { and Bert }\end{array}$ & Difference \\
\hline Baseline 1 & $\mathbf{4 4 8 5} \boldsymbol{k N}$ & $\mathbf{4 1 7 3} \boldsymbol{k N}$ & $\mathbf{6 . 9 6} \%$ \\
\hline Scaled 1.1 & $646 \mathrm{kN}$ & $594 \mathrm{kN}$ & $8.04 \%$ \\
Scaled 1.2 & $646 \mathrm{kN}$ & $542 \mathrm{kN}$ & $16.10 \%$ \\
\hline Baseline 2 & $\mathbf{8 3 6 8 \boldsymbol { k N }}$ & $\mathbf{7 8 3 4} \boldsymbol{k N}$ & $\mathbf{6 . 3 8} \%$ \\
\hline Scaled 2.1 & $829 \mathrm{kN}$ & $795 \mathrm{kN}$ & $1.20 \%$ \\
Scaled 2.2 & $829 \mathrm{kN}$ & $708 \mathrm{kN}$ & $14.45 \%$ \\
\hline
\end{tabular}

The Scaled 1.1 and 2.1 configurations were verified with finite-element analysis. Finite-element models of the baseline and scaled configurations were generated using the commercial general-purpose code Abaqus. ${ }^{15}$ Since the considered sandwich shells were relatively thin with thin cores, it was reasonable to model the core as a layer in a laminated shell. ${ }^{16,17}$ Thus S4R reduced-integration four-noded shell elements were used in the finite-element analysis. The scaled model used elements of approximately $10 \times 10 \mathrm{~mm}$ and the baseline model used elements of approximately $30 \times 30 \mathrm{~mm}$, which based on a convergence study, were converged mesh densities. Therefore, the baseline model had 77 elements in the axial direction and 252 elements in the circumferential direction. The Scaled 1.1 model had 134 elements in the axial direction and 251 elements in the circumferential direction; the Scaled 2.1 model had 125 elements in the axial direction and 251 elements in the circumferential direction. The boundary conditions were clamped with all degrees of freedom fixed at both ends of the shells, except free axial translation was allowed along the loaded edge. The loading in the finite-element analyses was the top edge displacement-controlled with a velocity of $1 \mathrm{~mm} / \mathrm{s}$. Explicit nonlinear dynamic analyses were performed in order to calculate the buckling load. The analytical and finite-element buckling loads are given and compared in Table 9. It is seen that the differences between the analytical and finite-element buckling loads were relatively small: $3.81 \%$ and $2.95 \%$ for Baseline 1 and 2, and $8.82 \%$

American Institute of Aeronautics and Astronautics 
and $1.10 \%$ for the Scaled 1.1 and Scaled 2.1, respectively. These differences were believed to be due to assumptions that were made in the development of the analytical methodology in neglecting the anisotropy effects and the influence of the transverse shear compliance, but which were included in the FEA.

Table 9. Comparison of analytical and finite-element buckling loads.

\begin{tabular}{cccc}
\hline Designation & $\begin{array}{c}\text { Analytical } \\
\text { Schultz and } \\
\text { Nemeth }\end{array}$ & Finite-element & Difference \\
\hline Baseline 1 & $\mathbf{4 4 8 5} \mathbf{k N}$ & $\mathbf{4 3 1 4} \mathbf{k N}$ & $3.81 \%$ \\
\hline Scaled 1.1 & $646 \mathrm{kN}$ & $589 \mathrm{kN}$ & $8.82 \%$ \\
\hline Baseline 2 & $\mathbf{8 3 6 8} \mathbf{k N}$ & $\mathbf{8 1 2 1} \mathbf{k N}$ & $\mathbf{2 . 9 5 \%}$ \\
\hline Scaled 2.1 & $829 \mathrm{kN}$ & $820 \mathrm{kN}$ & $1.10 \%$ \\
\hline
\end{tabular}

The load-displacement curves of the baseline and scaled are shown in Figure 6. The load of Baseline 1 is 7.3 times higher than the load for Scaled 1.1, whereas the load of Baseline 2 is 9.9 times higher than the load for Scaled 2.1. Regarding the displacement, both baseline structures reach the buckling load at $11.3 \mathrm{~mm}$. The Scaled 1.1 buckles at $1.9 \mathrm{~mm}$, while Scaled 2.1 reaches the buckling load at $2.3 \mathrm{~mm}$.

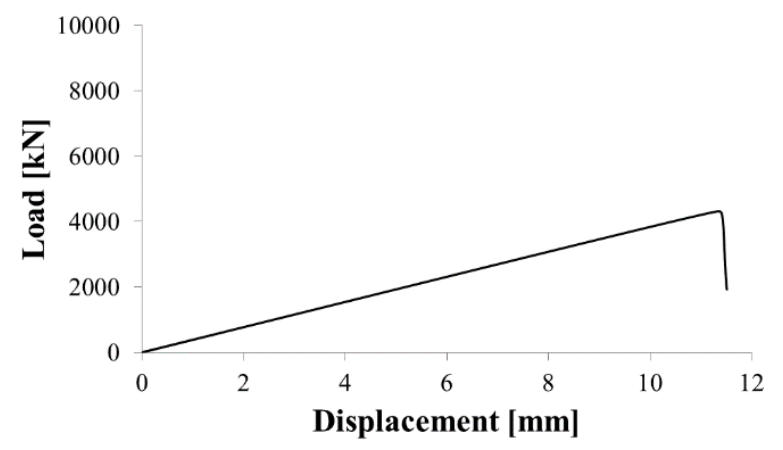

(a) Baseline 1

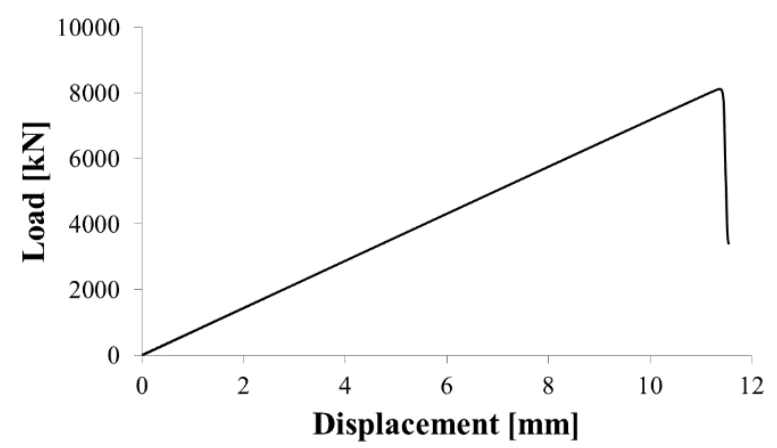

(c) Baseline 2

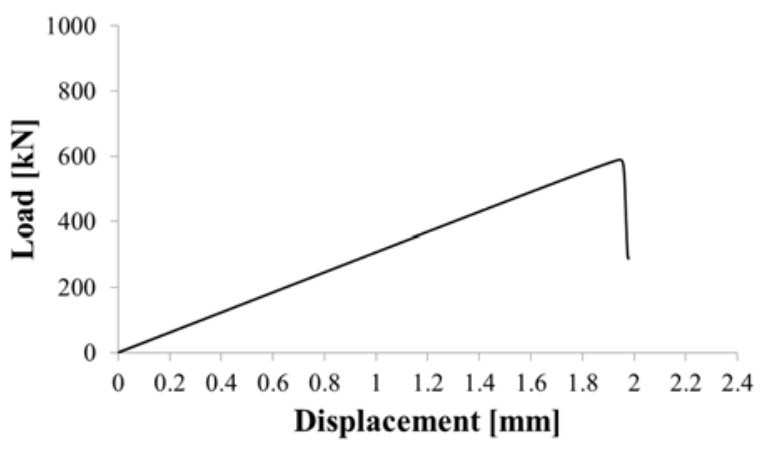

(b) Scaled 1.1

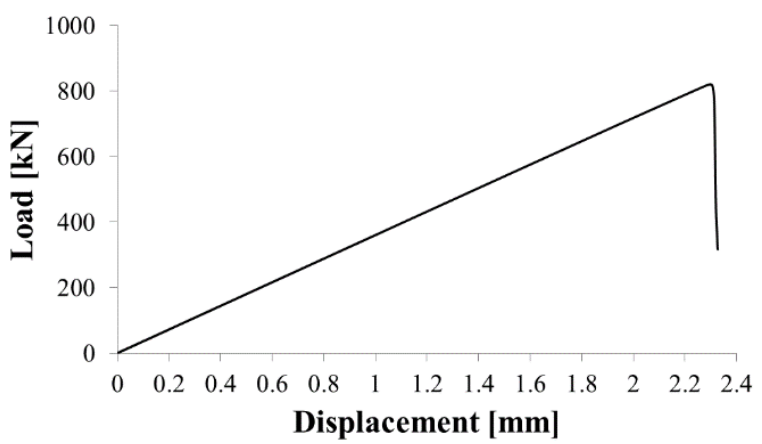

(d) Scaled 2.1

Figure 6. Load-displacement curves of baseline and scaled.

The strains from the innermost ply of the inner facesheet incipient to buckling are reported in Figure 7. There was a concentration of the strains in the edges of the cylinder for all cases. The predicted strain values for the baselines were $5518 \mu \varepsilon$ and $5653 \mu \varepsilon$, and the predicted strain values for the scaled configurations were $1388 \mu \varepsilon$ and $1797 \mu \varepsilon$. These scaled-configuration buckling strains were below typical failure strains for IM7/8552, ${ }^{10}$ so both these designs appear to be good candidates for effective buckling test articles. 

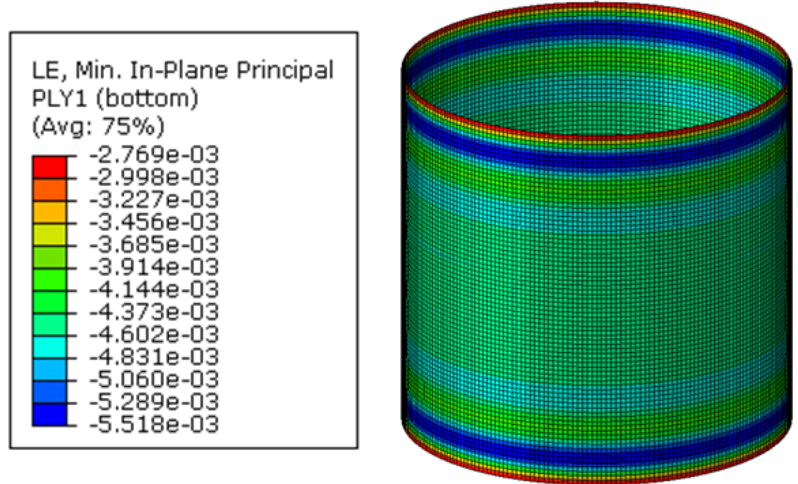

(a) Baseline 1
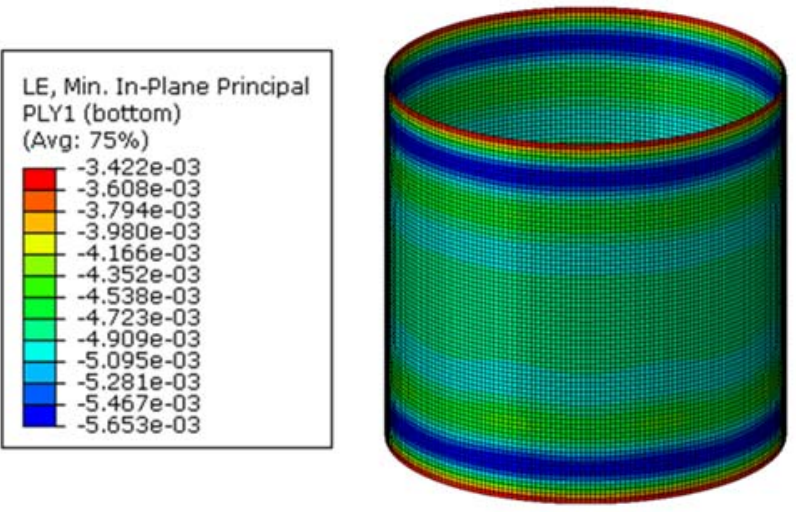

(c) Baseline 2
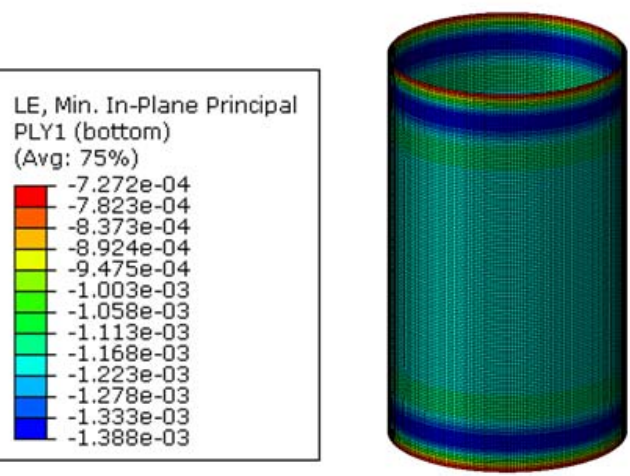

(b) Scaled 1.1
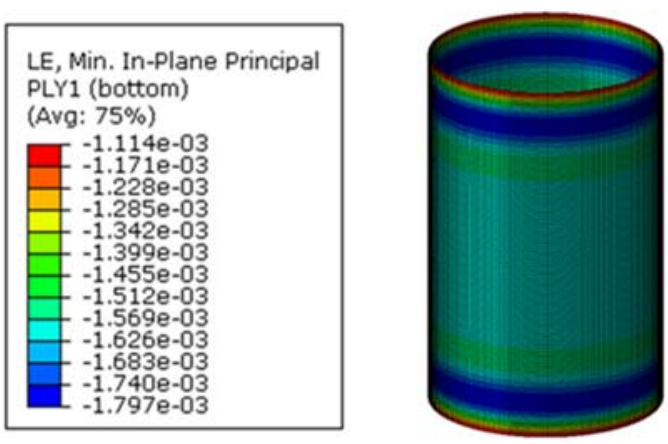

(d) Scaled 2.1

Figure 7. Prebuckling strains of innermost ply of baseline and scaled configurations.

The postbuckling behavior, was another indication of similarity in the baseline and scaled responses. The predicted postbuckling radial deformation patterns were quite similar, as shown in Figure 8. It was possible to observe two axial half waves and six circumferential full waves for all of the configurations. These postbuckled mode shapes were different from the analytically predicted buckling modes reported in Table 7. The postbuckled shapes showed characteristic long-wavelength diamond, or offset, patterns, and the analytically predicted buckling modes were shorter wavelength checkerboard patterns often predicted as linear buckling modes. 


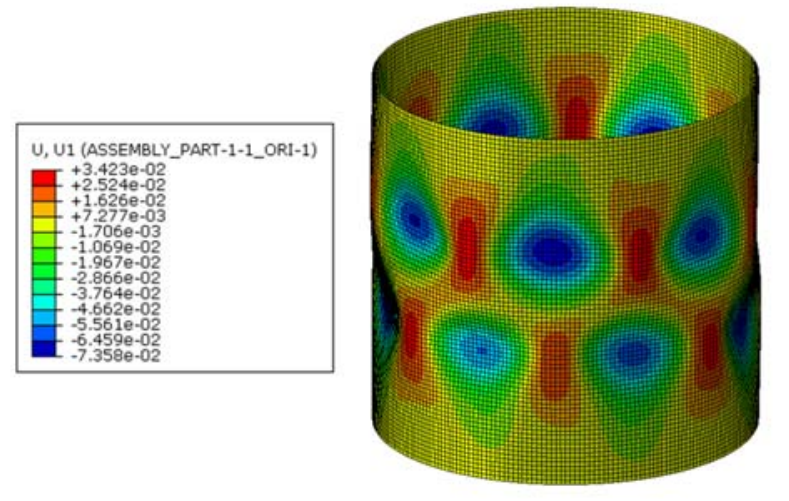

(a) Baseline 1

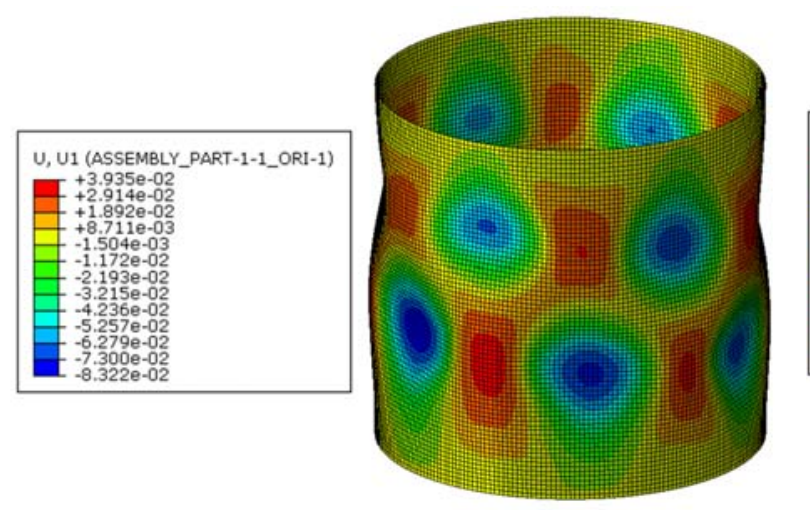

(c) Baseline 2
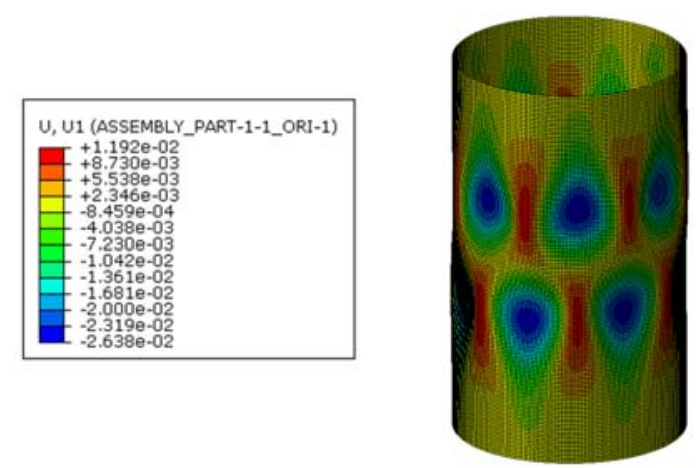

(b) Scaled 1.1
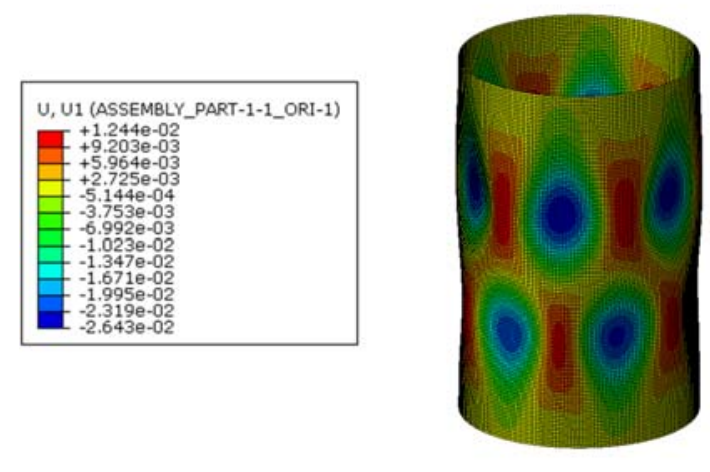

(d) Scaled 2.1

Figure 8. Postbuckling radial deformation of baseline and scaled configurations.

\section{Conclusions}

A scaling methodology for the buckling of sandwich composite cylindrical shells was described. The methodology was based on the nondimensionalization of the buckling equations and the study of the nondimensional parameters. In order to simplify the number of parameters involved, stacking sequences were chosen such that they were determined by a single ply angle, where the sandwich structures were considered balanced and symmetric. This allowed the scaling to be reduced to a three-step process: first, the facesheets stacking angle $\theta$ was determined; next, the geometry ratio, $\mathrm{R} / \mathrm{L}$, was determined, and finally the sandwich core thickness, $\mathrm{t}_{\text {core }}$, was determined. Through this process, it was possible to find scaled configurations with the same nondimensional parameters as those from the baseline configurations, which reproduce the buckling response.

The developed methodology was used to find scaled designs for two launch-vehicle-like baseline structures. The obtained scaled configurations have dimensions and buckling loads that can be applied with standard laboratory test equipment. The buckling responses of the baseline and scaled configurations were compared analytically and numerically. The scaled analytical buckling modes were found to be identical and the scaled analytical nondimensional load parameter $\mathrm{K}$ was within $0.5 \%$ for both baseline designs. The load-displacement curves, prebuckling strains and postbuckling shape were also shown as a measure of comparison between the baseline and scaled cylindrical shells.

The applicability of the methodology was limited by two initial simplifications: ignoring transverse-shear deformations and the flexural anisotropy parameters. The fact that these were neglected can explain some of the differences with the results of the finite-element analyses. Extending the methodology to include the transverse-shear and flexural anisotropy would likely extend the applicable range. 


\section{References}

${ }^{1}$ Bisagni, C., "Composite cylindrical shells under static and dynamic axial loading: An experimental campaign," Progress in Aerospace Sciences, vol. 78, 2015, pp. 107-115.

${ }^{2}$ Hilburger, M. W., "Developing the next generation shell buckling design factors and technologies," 53rd AIAA/ASME/ASCE/AHS/ASC Structures, Structural Dynamics and Materials Conference, paper AIAA 2012-1686.

${ }^{3}$ Sleight, D. W., Kosareo, D. N., and Thoma, S. D., "Composite interstage structural concept down select process and results," NASA NF1676L-13769, 2012, pp. 1-15.

${ }^{4}$ Schultz, M. R., Sleight, D. W., Myers, D. E., Waters, W. A. Jr., Chunchu, P. B., Lovejoy, A. W., and Hilburger, M. W., "Buckling design and imperfection sensitivity of sandwich composite launch-vehicle shell structures," Proceedings of American Society for Composites Technical Conference, 2016, n. 12029.

${ }^{5}$ Singer, J., Arbocz, J., and Weller, T., Buckling Experiments: Experimental Methods in Buckling of Thin Walled Structures. Volume 1, John Wiley and Sons, 1999.

${ }^{6}$ Rezaeepazhand, J., Simitses, G. J., and Starnes, J. H. Jr., "Scale models for laminated cylindrical shells subjected to axial compression," Composite Structures, vol. 34, 1996, pp. 371-379.

${ }^{7}$ Hilburger, M. W., Rose, C. A., and Starnes, J. H., Jr., "Nonlinear analysis and scaling laws for noncircular composite structures subjected to combined loads," $42^{\text {nd }}$ AIAA/ASME/ASCE/AHS/ASC Structures, Structural Dynamics and Materials Conference, paper AIAA 2001-1335.

${ }^{8}$ Schultz, M. R., and Nemeth, M. P., "Buckling imperfection sensitivity of axially compressed orthotropic cylinders," Proceedings of the 51st AIAA/ASME/ASCE/AHS/ASC Structures, Structural Dynamics and Materials Conference, 2010, paper AIAA 2010-2531.

${ }^{9}$ Przekop, A. P., Schultz, M. R., and Hilburger, M. W., "Design of buckling-critical large-scale sandwich composite cylinder test articles," Proceedings of the 59 ${ }^{\text {th }}$ AIAA/ASME/ASCE/AHS/ASC Structures, Structural Dynamics and Materials Conference, 2018, (submitted for publication).

${ }^{10}$ Marlett, K., Ng, Y., and Tomblin, J., "Hexcel 8552 IM7 unidirectional prepreg 190 gsm \& 35\% RC qualification material property data report," National Center for Advanced Materials Performance, Wichita, Kansas. Test Report CAM-RP-2009-015, Rev. A, 2011, pp. 1-238.

${ }^{11}$ Nemeth, M. P., "Nondimensional parameters and equations for buckling of symmetrically laminated thin elastic shallow shells," NASA TM 104060, 1991.

${ }^{12}$ Nemeth, M. P., "Nondimensional parameters and equations for nonlinear and bifurcation analyses of thin anisotropic quasi-shallow shells," NASA TP-2010-216726, 2010.

${ }^{13}$ Vinson, J. R., and Sierakowski, R. L., The Behavior of Structures Composed of Composite Materials. Springer Science \& Business Media, 2012.

${ }^{14}$ Reese, C. D., and Bert, C. W., "Buckling of orthotropic sandwich cylinders under axial compression and bending," Journal of Aircraft, vol. 11, 1974, pp. 207-212.

${ }^{15}$ Abaqus/Standard, Software Package, Ver. 2017, Dassault Systèmes, Waltham, MA, 2014.

${ }^{16}$ Bisagni, C., "Numerical analysis and experimental correlation of composite shell buckling and post-buckling," Composites Part B: Engineering, vol. 31, 2000, pp. 655-667.

${ }^{17}$ Alfano, M., and Bisagni, C., "Probability-based methodology for buckling investigation of sandwich composite shells with and without cut-outs," International Journal for Computational Methods in Engineering Science and Mechanics, vol. 18, 2017, pp. 77-90. 